\title{
DAMPAK SOSIAL OMNIBUS LAW CIPTA KERJA PERSPEKTIF SOSIOLOGI HUKUM
}

\author{
Hanifah Az Zahra ${ }^{*}$, Agus Machfud Fauzi² \\ 12 Universitas Negeri Surabaya, Indonesia \\ *Correspondence: hanifah.19035@mhs.unesa.ac.id
}

Received: 25 November 2020; Accepted: Februari 2021; Published: 31 Maret 2021

\begin{abstract}
Government policies by legitimizing the presence of the omnibus law on copyright work, socially and legally have an impact on labor and workers. The reason is that this controversial law is considered to be very detrimental to labor and workers. The purpose of this study was to analyze the extent to which social impacts were generated after the government legal sociological perspective of the work copyright omnibus law was passed. This study uses a qualitative approach and descriptive methods and is equipped with literature study data collection. The results of the study conclude that the sociology of law responds to the rejection of the omnibus law on work copyright done by workers and labor because it will have an effect on social impacts that have implications for demonstrations of labor and workers nationally.
\end{abstract}

Keywords : omnibus law; rejection; sociology of law

\begin{abstract}
Abstrak
Kebijakan pemerintah dengan melegitimasi hadirnya omnibus law cipta kerja, secara sosial dan hukum berdampak terhadap buruh dan tenaga kerja. Pasalnya Undang-undang kontroversi ini dipandang akan sangat merugikan buruh dan tenaga kerja. Tujuan penelitian ini adalah untuk menganalisis sejauh mana dampak sosial yang ditimbukan pasca disahkannya omnibus law cipta kerja oleh pemerintah perspektif sosiologi hukum. Penelitian ini menggunakan pendekatan kualitatif dan metode deskriptif serta dilengkapi dengan pengumpulan data studi pustaka. Hasil penelitian menyimpulkan bahwa sosiologi hukum merespon terhadap penolakan omnibus law cipta kerja yang dilakukan oleh buruh dan tenaga kerja karena akan berpengaruh terhadap dampak sosial yang berimplikasi pada aksi demonstrasi para buruh dan tenaga kerja secara nasional.
\end{abstract}

Kata Kunci : omnibus law, penolakan, sosiologi hukum 


\section{Pendahuluan}

Indonesia menjadi salah satu negera dengan peraturan perundanganundangan yang cukup banyak sebagai upaya pemerintah dalam melaksanakan program kerjanya dibidang legislasi. Tetapi peraturan perundangan-undangan yang banyak itu tidak semuanya menjadi harapan bagi pemerintah, sehingga dipandang perlu dilakukan upaya penyederhanaan agar tidak terjadi tumpang tindik antara peraturan yang satu dengan yang lainnya. Konsep penyederhanaan tersebut dikenal dengan istilah omnibus law.

Omnibus law pertama kali diperkenalkan oleh Ir. Joko Widodo pada saat menyampaikan pidato kenegaraan dalam rangka pelantikannya sebagai Presiden Republik Indonesia ke-7 Periode ke-2 di hadapan sidang MPR-RI. ${ }^{1}$ Omnibus law merupakan konsep yang baru digunakan dalam sistem perundang-undangan di Indonesia. Sistem ini biasanya disebut sebagai Undang-Undang sapu jagat karena mampu mengganti beberapa norma undang-undang dalam satu peraturan. Selain itu konsep ini juga dijadikan misi untuk memangkas beberapa norma yang dianggap tidak sesuai dengan perkembangan zaman dan merugikan kepentingan negara. ${ }^{2}$

Negara dengan sistem hukum Anglo Saxon Common Law telah lebih dulu menggunakan konsep omnibus law dalam pembuatan peraturan perundangundangannya. Sebut saja Amerika, Kanada, Irlandia, dan Suriname. Sedangkan di Asia Tenggara, Vietnam menjadi negara pertama yang mencoba mengimplementasikan penerapan omnibus law sebagaimana hasil aksesi dengan WTO pada tahun 2006.

Aturan-aturan yang dianggap tumpang tindih dan menjadi penyebab terhambatnya investasi serta pertumbuhan ekonomi negara menjadi salah satu ikhwal digagasnya konsep omnibus law, sehingga memudahkan untuk dilakukan sinkronisasi terhadap produk hukum yang besar. ${ }^{3}$ Permasalahan over regulasi dan tumpang tindih dapat diselesaikan dengan konsep omnibus law. ${ }^{4}$

Saat konsep omnibus law cipta kerja mulai diberitakan kepada masyarakat. Konsep ini menjadi perbincangan hangat diberagai kalangan masyarakat, mulai dari kalangan atas, menengah, dan bahkan daari kalangan bawah. Konsep ini sangat tidak disetujui oleh kalangan bawah terutaman bagi kalangan buruh. Konsep ini dianggap merugkan baginya dan menguntungkan kalangan atas. Konsep ini membuat heboh bagi kalangan buruh. Menimbulkan perdebatan

1 Adhi Setyo Prabowo, "Politik Hukum Omnibus Law Di Indonesia," Jurnal Pamator 17, no. 1 (2020).

2 Dwi Kusumo Wardhani, "Disharmoni Antara Ruu Cipta Kerja Bab Pertanahan Dengan Prinsip-Prinsip UU Nomor 5 Tahun 1960 Tentang Peraturan Dasar Pokok-Pokok Agraria (UUPA)," Jurnal Komunikasi Hukum (JKH) Universitas Pendidikan Ganesha 6, no. 2 (2020): 440.

3 Antoni Putra, "Penerapan Omnibus Law Dalam Upaya Reformasi Regulas," Jurnal Legislasi Indonesia 17 , no. 1 (2020).

4 Ansari Muhamad Insan, “Omnibus Law Untuk Menata Regulasi Penanaman Modal," Jurnal RechtsVending 9, no. 1 (2020). 
yang sengit dan alot antara para buruh dengan pemerintah. Dampak yang diterima oleh kalangan tersebut pun beragam.

Hasil penelitian Putra yang menitik beratkan pada kajian omnibus law sebagai konsep hukum yang berfokus pada penyederhanaan jumlah regulasi. ${ }^{5}$ Penelitian tersebut juga dilakukan oleh Harsono yang menyatakan bahwa Omnibus law merupakan metode dalam proses pembuatan atau penyusunan aturan hukum, bukan jenis peraturan perundang-undangan. Selanjutnya, Harsono menitikberatkan kasus omnibus law pada masa covid-19. ${ }^{6}$ Penelitian lain juga dilakukan oleh Cakra dan Sulistyawan yang menfokuskan pada bagaimana penerapan Omnibus Law di dalam sistem pembentukan peraturan perundangan Indonesia. ${ }^{7}$ Penelitianpenelitian tersebut menitik beratkan pada telaah kajian omnilaw law secara konsep. Adapun penelitian ini menitik beratkan pada bagaimana sosiologi hukum memandang kericuhan omnibus law itu sendiri.

Tujuan penelitian ini untuk menganalisis dampak sosial omnibus law cipta kerja perspektif sosiologi hukum. Analisis ini diharapkan dapat merangsang kepekaan generasi bangsa untuk peduli terhadap pemerintah dalam membenahi kebijakan-kebijakan regulasi yang dibuat. Selain itu, generasi bangsa mampu menjadi agen perubahan untuk pengembangan berbagai jenis sumber daya baik SDM maupun SDA yang ada. Selanjutnya mampu berinovasi untuk memajukan Negara Indonesia ke arah yang lebih baik.

\section{Metodologi}

Metode yang digunakan dalam penelitian ini adalah kualitatif deskriptif dengan mengumpulkan berbagai sumber dan pemahaman nyata sebagai teknik pengumpulan data deskriptif. Menurut Nawawi ${ }^{8}$ metode deskriptif dapat diartikan sebagai prosedur pemecahan masalah yang diselidiki dengan menggambarkan/ melukiskan keadaan subjek/objek artikel (seseorang, lembaga, masyarakat, dan lainlain) pada saat sekarang berdasarkan fakta-fakta yang tampak atau sebagaimana adanya. Metode deksriptif adalah suatu pemecahan masalah yang berusaha menggambarkan kenyataan yang terjadi. Penelitian kualitatif digunakan untuk menggambarkan suatu keadaan dengan apa adanya tanpa menggunakan angkaangka. Moleong" "artikel kualitatif adalah data yang dikumpulkan berupa katakata, gambar, dan bukan angka". Data yang dipergunakan dalam penelitian ini dinyatakan dalam bentuk kalimat serta uraian-uraian atau pernyataan.

5 Putra, "Penerapan Omnibus Law Dalam Upaya Reformasi Regulas."

6 Harsono, "Problematika Omnibus Law Cipta Lapangan Kerja Di Masa Pandemi Covid 19 (Antara Impian Dan Harapan Pemerintah Indonesia)," Al Qodiri: Jurnal Pendidikan, Sosial Dan Keagamaan 18, no. 3 (2020): 594-603.

7 I Putu Eka Sulistyawan Cakra and Aditya Yuli, "Kompabilitas Penerapan Konsep Omnibus Law Dalam Sistem Hukum Indonesia.," Jurnal Crepido 02, no. 02 (2020): 59-69.

8 Hadari Nawawi, Metode Penelitian Bidang Sosial (Yogyakarta: UGM Press., 1991).

9 Lexy J Moleong, Metodologi Penelitian Kualitatif (Bandung: PT. Remaja Rosdakarya, 2008). 


\section{Hasil dan Pembahasan}

\section{Respon Sosiologi Hukum Terhadap Penolakan Omnibus Law Cipta Kerja}

Seyogyanya Pemerintah terlebih dahulu melakukan analisis yang berkesinambungan sebelum membuat dan mensahkan omnibus law cipta kerja menjadi Undang-Undang sapu jagat. Karna peraturan ini akan berdampak signifikan terhadap sosial, hukum, dan ekonomi bangsa Indonesia. Selanjutnya perhatian tersebut harus ditujukan terhadap dampak positif dan negatif berbagai sektor, baik kalangan atas, menengah, maupun bawah. Pemerintah dengan kapasitasnya harus dapat menganalisis secara seksama, dalam hal ini dapat ditarik dari sudut pandangan teori sosiologi fungsional. Secara subtansi, omnibus law cipta kerja pada prinsipnya harus memiliki dasar pertimbangan, diantaranya "rasionalitas, validitas, visibilitas filosofi, yuridis, dan sosiologi yang paralel". Sehingga setelah pertimbangan ini dilakukan secara matang pastikan masyarakat dapat menerimanya dengan baik serta masyarakat memandang aturan ini layak secara legitimasi.

Pemerintah dapat menggunakan alternatif teori tersebut agar menjadi alat analisis terhadap masyarakat dari faktor dan peranan masing-masing individu. Indonesia sebagai negara dengan sistem trias politikanya dapat menjalankan prinsip tersebut mulai dari gagasan negara dari rakyat, oleh rakyat dan untuk rakyat, hal hal tersebut harus dapat direlaisasikan, terutama dihadapkan dengan semakin beragamnya aturan yang diterapkan oleh pemerintah dalam mengatur masyarakatnya. Pasalnya bahwa aturan yang dibuat oleh pemerintah bukan lagi untuk kepentingan rakyat secara menyeluruh, namun hanya untuk kalangan tertentu saja. Sehingga dengan munculnya omnibus law cipta kerja seharusnya dapat memastikan kepentingan rakyat menjadi tidak dikerdilkan. Karena itu, semua keputusan yang diambil oleh para pemangku kepentingan harus mengedepankan asas kesejahteraan terhadap masyarakat.

Konsep omnibus law khususnya Undang-Undang Cipta Kerja sejatinya dapat menjadi solusi untuk menyederhanakan peraturan yang terlalu banyak, seperti yang dialami Indonesia saat ini. Menurut Antoni Putra dari Peneliti Pusat Studi Hukum dan Kebijakan Indonesia memberikan pandangan bahwa selain regulasi yang terlalu banyak, terdapat beberapa permasalahan mendasar lainnya. Pertama, tidak sinkronnya perencanaan peraturan perundang- undangan, baik di tingkat pusat maupun daerah dengan perencanaan dan kebijakan pembangunan. Kedua, adanya kecenderungan peraturan perundang-undangan menyimpang dari materi muatan yang seharusnya diatur. Ketiga, ketidaktaatan terhadap materi muatan tersebut memunculkan persoalan "hiper-regulasi". Keempat, efektivitas peraturan perundang-undangan juga sering menjadi persoalan yang muncul pada saat implementasi. Keadaan diperburuk dengan tidak adanya prosedur pemantauan dan evaluasi peraturan perundang-undangan serta ketiadaan lembaga khusus yang menangani seluruh aspek dalam sistem peraturan perundang-undangan. ${ }^{10}$

10 Putra, "Penerapan Omnibus Law Dalam Upaya Reformasi Regulas." 
Penerapan konsep omnibus law bukan tanpa pertimbangan. Semua memiliki kelebihan dan kekurangannya. Kaitan penerapan bangunan model arsitektur omnibus law dalam sistem hukum nasional melalui literasi yang telah dilakukan pemerintah, penerapannya pun dilakukan melalui kajian rasio logis pembuatan suatu undang-undang dengan metode omnibus law dengan pendekatan komparatif yang substantif, konstruktif dan transgresif, di Indonesia dan negara lain.

Selanjutnya penetapan omnibus law cipta kerja menjadi Undang-undang disahkan oleh DPR-RI pada saat pandemi covid-19 masih mewabah. Keadaan itu sangat disayangkan dan mengejutkan publik. Khususnya bagi kalangan akademisi, pelajar, mahasiswa hingga buruh. Sejumlah aksi demonstrasi dilakukan untuk menolak peraturan baru tersebut, tetapi DPR-RI seolah menutup mata dan telinga sehingga tetap mengesahkannya pada tanggal 5 Oktober 2020. Kemudian Omnibus law cipta kerja itu tanpa banyak pertimbangan kembali disetujuai dan ditandatangani Presiden Joko Widodo dan resmi diundangkan dengan Undang-Undang Nomor 11 Tahun 2020 tentang Cipta Kerja. ${ }^{11}$

Sebelum Undang-Undang Nomor 11 Tahun 2020 tentang Cipta Kerja disahkan oleh Pemerintah. Buruh dan Tenaga Kerja di beberapa daerah telah melakukan aksi demonstrasi agar omnibus law ini ditunda dan/atau dibatalkan. Termasuk aksi demonstrasi yang dilakukan di Provinsi DKI Jakarta sebagai Ibu Kota Negara. Para buruh, akademisi, mahasiswa, dan pelajar turut melakukan aksi turun ke jalan menentang omnibus law cipta kerja. Masyarakat beranggapan bahwa kehadiran omnibus law cipta kerja akan merugikan masyarakat bawah terutama buruh dan tenaga kerja. Ada beberapa pasal dan ayat dalam RUU Cipta Kerja yang kontradiktif bahkan masih kontroversi sehingga cenderung merugikan rakyat dan lebih menguntungkan para pengusaha.

Ratusan massa yang tergabung dalam Konfederasi Serikat Buruh Seluruh Indonesia (KSBSI) menggelar aksi di sekitar Istana Jakarta, kawasan Patung Kuda, Jalan Medan Merdeka Barat. Bahkan Konfederasi Serikat Pekerja Indonesia (KSPI) mengklaim sebanyak 2 juta buruh dari 10 ribu perusahaan di 25 Provinsi akan melakukan aksi mogok nasional yang berlokasi di lingkungan perusahaan masing-masing dalam rentang waktu 6 sampai dengan 8 Oktober 2020. Para buruh akan terus berusaha memperjuangkan haknya dalam bekerja. Buruh beranggapan bahwa isi/subtansi baik dari pasal maupun ayat omnibus law cipta kerja sangat tidak menguntungkan.

11 Ardi Ahmad Ulil, "Teknik Pengumpulan Data," Jurnal Ilmiah Kebijakan Hukum. 14, no. 1 (2020). 


\section{Gambar 1}

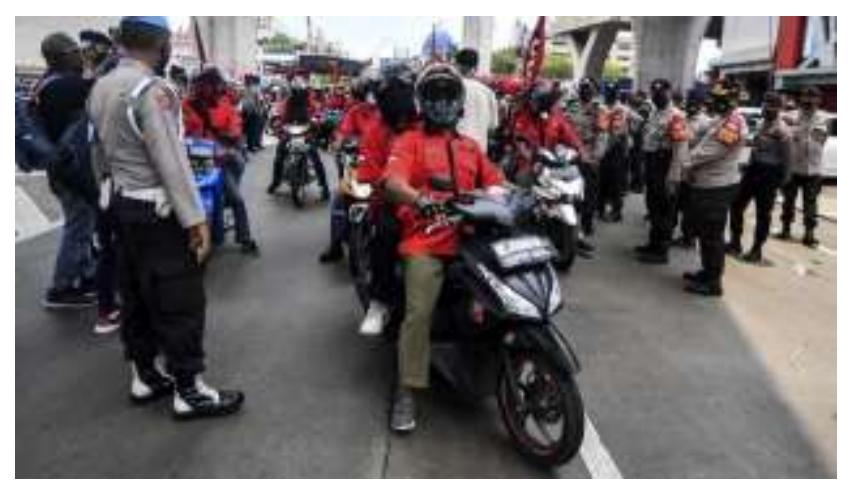

Sumber: BCC News

Dalam gambar tampak kerumunan massa dari Konfederasi Persatuan Buruh Indonesia (KPBI) melakukan aksi massa untuk menolak omnibus law cipta kerja di Tanjung Priok pada hari Selasa tanggal 06 Oktober 2020. Aksi ini dikawal ketat aparat hingga tanpa insiden berarti. ${ }^{12}$ Unjuk masa omnibus law cipta kerja tak hanya dilakukan oleh para buruh tetapi dilakukan juga oleh para mahasiswa dan pelajar. Penolakan omnibus law cipta kerja tidak hanya dilakukan di Jakarta tetapi dilakukan di beberapa kota besar Indonesia. Seperti Semarang, Bandung, Banten, Surabaya, Makasar, Bekasi, Yogyakarta, Malang, dan beberapa daerah besar lainnya.

Konsep omnibus law cipta kerja perlu mendapat perlakuan khusus untuk dilakukan kajian secara terstruktur dari beragai bidang pengetahuan, salah satunya kajian bidang sosiologi hukum. Sosiologi Hukum merupakan disiplin ilmu yang sudah sangat berkembang. Pada prinsipnya, sosiologi hukum (Sociology) of Law) merupakan derivatif atau cabang dari Ilmu Sosiologi, bukan cabang dari ilmu hukum. Ada studi tentang hukum yang berkenaan dengan masyarakat yang merupakan cabang dari ilmu hukum, tetapi tidak disebut sebagai Sosiologi Hukum, melainkan disebut sebagai Sociological Jurispudence. ${ }^{13}$

Dalam lingkup sosiologi hukum sendiri penolakan omnibus law cipta kerja sangat dipertimbangkan. Pengesahan omnibus law cipta kerja terkesan sangat buru-buru tanpa mempertimbangkan lebih dalam bagaimana dampak sosial, hukum, dan ekonomi Indonesia ke depan. Beberapa orang pun beranggapan bahwa omnibus law cipta kerja sangat menguntungkan piha-pihak tertentu yaitu para pengusaha yang berinvestasi di Indonesia. Namun kalangan buruh dan tenaga kerja dirugikan.

12 BCC News, "Omnibus Law Cipta Kerja Picu Unjuk Rasa Yang Diwarnai Tembakan Meriam Air Dan Gas Air Mata, Menaker: "Ayo Kita Dialog," 2020, https://www.bbc.com/indonesia/indonesia-54431015.

13 M. Chairul Basrun Umanailo, Sosiologi Hukum (FAM Publisher, 2013). 
Pengesahan omnibus law cipta kerja pada tanggal 5 Oktober 2020 oleh DPR-RI memicu aksi penolakan dari buruh, akademisi, mahasiswa, dan kelompok masyarakat sipil di sejumlah daerah. ${ }^{14}$ Sejumlah pasal krusial menjadi sorotan karena dinilai banyak hal yang akan dipertaruhkan dan kontradiktif dengan spirit Undangundang tersebut. Beberapa pasal diantaranya tentang: Pertama Penghapusan upah minimum. Kedua, jam lembur menjadi lebih lama. Ketiga, Kontrak seumur hidup. Keempat, pemutusan hubungan kerja sewaktu-waktu. Kelima, Pemotongan waktu istirahat, dan Keenam, Mempermudah perekrutan Tenaga Kerja Asing, dinilai sangat merugikan buruh dan tenaga kerja lokal. Sehingga hal ini tentunya akan berdampak juga pada lingkungan dan pendidikan.

Berdasarkan hipotesis sosial, apabila aturan yang dikeluarkan oleh pemerintah mengalami penolakan yang semakin tinggi dari masyarakat, maka legitimasi sosial aturan tersebut semakin rendah. Tiga hal legitimasi sosial yang berdampak terhadap produk peraturan perundang-undangan yang dibuat oleh pemerintah berdasarkan sosiologis:

Pertama, Social Materiality Assessment, hal ini berkaitan dengan sejauh mana peran pemerintah bersama DPR dalam membuat aturan harus didasarkan pada aspek penggalian dan pemilihan bahan-bahan sosial harus bersumber dari pandangan masyarakat yang dapat dipertanggungjawabkan aspirasinya dengan fakta-fakta sosial yang berkembang. Pemerintah harus memperhatikan suasana kebatinan masyarakat, sehingga kepentingan-kepentingan sosialnya dapat tersampaikan melalui norma-norma hukum itu sendiri. Bukan sekedar mempertimbangkan segelincir elite tanpa memandang suasana batin rakyat.

Kedua, Kurang terbuka dan transparan wakil rakyat dalam membuat regulasi, sehingga berdampak pada lemahnya proses dan prosedur pembahasan aturan. Sebagaimana dengan sikap tergesa-gesanya DPR-RI dalam mengesahkan omnibus law cipta kerja disaat kondisi pandemi covid-19, dipandang oleh masyarakat sebagai sikap "kejar tayang" bukan untuk kepentingan rakyat, tetapi hanya untuk kepentingan elite-elite tertentu. Alhasil rakyat menilai omnibus law cipta kerja cacat prosedur.

Ketiga, Lemahnya subtansi atau isi yang diatur. Terdapat beberapa Pasal dalam Undang-Undang Nomor 11 Tahun 2020 tentang Cipta Kerja, diantaranya (1) penghapusan upah minimum; (2) jam lembur menjadi lebih lama; (3) kontrak seumur hidup; (4) pemutusan hubungan kerja sewaktu-waktu; (5) pemotongan waktu istirahat; dan (6) mempermudah perekrutan Tenaga Kerja Asing, dinilai sangat merugikan buruh dan tenaga kerja lokal Karena itu, wajar jika publik menilai, Undang-Undang Cipta Kerja ini cacat secara substansi”.

14 Nur Fitriatus Shalihah. Kompas.com dengan judul "Aksi Demo Penolakan Omnibus Law UU Cipta Kerja di 9 Daerah Berlangsung Ricuh, Mana Saja?", Dipublikasikan pada 8 Oktober 2020. Pukul 18:05 WIB https://www.kompas.com/tren/read/2020/10/08/180500765/aksidemo-penolakan-omnibus-law-uu-cipta-kerja-di-9-daerah-berlangsung?page=all . 


\section{Kesimpulan}

Omnibus law sebagai sautu undang-undang dengan menitikberatkan terhadap penyederhanaan dari beberapa peraturan perundang-undangan yang sifatnya merevisi atau mencabut sekaligus. Omnibus law saat ini telah secara resmi disahkan pemerintah pada saat pandemi dengan nama Omnibus Law Cipta Kerja. Pengesahan ini sangat mengejutkan publik, terutama bagi para akademisi, pelajar, mahasiswa, dan para buruh yang paling berdampak besar. Perspektif sosiologi hukum menganggap bahwa penolakan tersebut pasti akan terjadi, namun dalam merespon penolakan tersebut harus memikirkan kelebihan dan kekurangan dalam setiap tindakan yang akan dilakukan. Bagi pemerintah dalam mengambil setiap kebijakan setidaknya harus memperhitungkan secara matang konsekwensi yang akan timbul dari diberlakukannya suatu aturan perundangundangan, terutama dalam mensejahterakan kehidupan rakyat.

\section{Daftar Pustaka}

Cakra, I Putu Eka Sulistyawan, and Aditya Yuli. "Kompabilitas Penerapan Konsep Omnibus Law Dalam Sistem Hukum Indonesia." Jurnal Crepido 02, no. 02 (2020): 59-69.

CNN Indonesia. "Demo Tolak Omnibus Law: Panas di Daerah, Adem di Jakarta”. Dipublikasikan pada Rabu, 7 Oktober 2020. Pukul 07:34 WIB. https://www.cnnindonesia.com/nasional/20201007064929-20-

555237 /demo-tolak-omnibus-law-panas-di-daerah-adem-di-jakarta

Harsono. "Problematika Omnibus Law Cipta Lapangan Kerja Di Masa

Pandemi Covid 19 (Antara Impian Dan Harapan Pemerintah Indonesia)." Al Qodiri: Jurnal Pendidikan, Sosial Dan Keagamaan 18, no. 3 (2020): 594-603.

Insan, Ansari Muhamad. "Omnibus Law Untuk Menata Regulasi Penanaman Modal." Jurnal RechtsVending 9, no. 1 (2020).

Moleong, Lexy J. Metodologi Penelitian Kualitatif. Bandung: PT. Remaja Rosdakarya, 2008.

Nawawi, Hadari. Metode Penelitian Bidang Sosial. Yogyakarta: UGM Press., 1991.

News, BCC. "Omnibus Law Cipta Kerja Picu Unjuk Rasa Yang Diwarnai Tembakan Meriam Air Dan Gas Air Mata, Menaker: 'Ayo Kita Dialog,"” 2020. https://www.bbc.com/indonesia/indonesia-54431015.

Prabowo, Adhi Setyo. "Politik Hukum Omnibus Law Di Indonesia." Jurnal Pamator 17, no. 1 (2020).

Putra, Antoni. "Penerapan Omnibus Law Dalam Upaya Reformasi Regulas." Jurnal Legislasi Indonesia 17, no. 1 (2020).

Ulil, Ardi Ahmad. "Teknik Pengumpulan Data." Jurnal Ilmiah Kebijakan Hukum. 14, no. 1 (2020). 
Umanailo, M. Chairul Basrun. Sosiologi Hukum. FAM Publisher, 2013.

Wardhani, Dwi Kusumo. "Disharmoni Antara Ruu Cipta Kerja Bab Pertanahan Dengan Prinsip-Prinsip UU Nomor 5 Tahun 1960 Tentang Peraturan Dasar Pokok-Pokok Agraria (UUPA)." Jurnal Komunikasi Hukum (JKH) Universitas Pendidikan Ganesha 6, no. 2 (2020): 440. 
C 2021 by the authors. Submitted for possible open access publication under the terms and conditions of the Creative Commons Attribution (CC BY SA) license (https://creativecommons.org/licenses/by-sa/3.0/). 